\title{
Knowledge, Attitude, and Practice Towards Biosimilars and Interchangeable Products: A Prescriptive Insight by the Pharmacists
}

This article was published in the following Dove Press journal: International Journal of General Medicine

\author{
Sadia Shakeel ${ }^{1,2}$ \\ Mohamed Azmi Hassali (D) \\ Hina Rehman ${ }^{3}$ \\ Anees ur Rehman (1D) ${ }^{1,4}$ \\ Jaya Muneswarao' \\ 'Discipline of Social and Administrative \\ Pharmacy, School of Pharmaceutical \\ Sciences, University Sains Malaysia, \\ Penang, Malaysia; ${ }^{2}$ Faculty of \\ Pharmaceutical Sciences, Dow University \\ of Health Sciences, Karachi, Pakistan; \\ ${ }^{3}$ Institute of Pharmaceutical Sciences, \\ Jinnah Sind Medical University, Karachi, \\ Pakistan; ${ }^{4}$ Faculty of Pharmacy, Bahauddin \\ Zakariya University, Multan, Pakistan
}

Correspondence: Sadia Shakeel Email sadiashakeel@usm.my
Background: Pharmacists being the drug experts need to be well aware of the applied handling of biosimilar medicines (BSMs). They are an integral educator, trailblazer, and advocate of biosimilar integration across all clinical settings. Therefore, the current study was conducted to assess the pharmacists' knowledge, attitude, and practices of integrating BSMs into clinical practice.

Methods: The cross-sectional study was conducted from August 2019 to November 2019. The community pharmacies, clinical and academic settings in Karachi were approached for gathering the responses of pharmacists towards BSMs and interchangeable products using a 30-item survey form. Pearson correlation and independent sample $t$-test were used to identify the relationship among independent variables and the responses, considering $\mathrm{p}$ values $<0.05$ as statistically significant.

Results: Overall, there were 305 survey forms used with a response rate of $87.14 \%$. More than $80 \%$ of the respondents have good knowledge about the definition, characteristics, safety and efficacy, compatibility, cost issues, and utilization of BSMs. Around half of the respondents (48.9\%, [95\% CI 46.6-51.2]) were confident in using BSMs in clinical practice. However, they were concerned about the BSM's safety profile (45.2\%, [95\% CI 42.1-48.3]), quality (30.2\%, [95\% CI 28.3-32.1]), and efficacy issues (32.3\%, [95\% CI 31.2-37.5]).

Conclusion: The findings revealed that pharmacists were well informed about the BSMs. However, some of the responses to the attitude demonstrated a lack of understanding of the application of that knowledge. The respondents persuaded that advanced patterns of diseases, product marketing stipulations, and need for better patient care drives higher demand for developing BSMs and were enthusiastic about gaining more insight to integrate BSMs into routine clinical practice.

Keywords: pharmacists, biosimilar medicines, interchangeable products, healthcare, Pakistan

\section{Introduction}

Biosimilars (BSMs) are medicinal products that are the replications of original biopharmaceuticals. They imitate the unique innovation prompting the generation of advanced biotech medicines for a product like the original one. BSMs have stamped acknowledgment in national and worldwide pharmaceutical business. As they are cost-effective and easily available; BSMs have perceived a remarkable position in healthcare field. ${ }^{1,2}$ However, it should be considered that BSMs are not the generics of biological products and they require much robust standards for the 
assessment of quality, efficiency, and safety as compared to generic products. ${ }^{3}$ BSMs are approved based on various equivalence steps that show high comparability to the Food and Drug Administration (FDA) endorsed originator biologic and have exhibited no clinically significant contrasts in quality, wellbeing, and adequacy. ${ }^{4}$ An interchangeable product is a BSM that fulfills added requirements as defined by the Biologics Price Competition and Innovation Act. Additional information is necessary to show that an interchangeable product is anticipated to produce a similar clinical outcome as the reference product in the patient. The high standards of FDA for approving interchangeable products make sure that healthcare professionals must be confident in the safety and efficiency, similarly as they would be for an FDA-approved reference product. ${ }^{5,6}$

Debates in regards to BSMs started in the late 1990s when the patent of some best-selling biopharmaceutical drugs get expired. It was comprehended in 1984 that the Hatch-Waxman Act or Drug Price Competition and Patent Term Restoration Act, an enactment which coordinates the commercialization and extension of generic copies of lowmolecular-weight drugs, did not provide a lawful administrative organizational structure for the endorsement of this particular class in the USA. ${ }^{5}$ Likewise, in Europe or elsewhere globally there was no regulation for the authorization of BSMs. ${ }^{6}$ This initiated conversations about the need for commercialization of BSMs in the pharmaceutical market. BSMs faced the opposition with various pacesetter pharmaceutical organizations having good financial plans. At last, the European Medications Agency (EMA) in 2005 organized administrative supervision for the endorsement of BSMs in the European Union (EU). ${ }^{7}$ Advanced patterns of disease, product marketing stipulations, and need for better patient care drives higher business opportunities for companies developing BSMs. Besides, the reason behind the widespread use includes lower prices related to the reference biologics. As of March 2018, there are currently more than 40 EUapproved BSMs, across 15 different biological classes. ${ }_{-}^{8-10}$

Internationally recognized regulatory bodies such as EMA, FDA, World Health Organization (WHO), and International Federation of Pharmaceutical Manufacturers and Associations (IFPMA) proposes a simplified and abbreviated approval process for BSMs that may facilitate the process of BSMs commercialization. The WHO contributes significantly to monitoring drug quality in developing countries through its prequalification program to make sure that treatments supplied by U.N. agencies are of standard quality. ${ }^{11,12}$ Pakistan is following the good manufacturing practices as suggested by international regulatory bodies for the production of BSMs. Pharmaceutical regulation is directed by the Drug Regulatory Authority of Pakistan (DRAP) to makes sure the enactment of the Drugs Act, 1976 (XXXI of 1976). ${ }^{9,10}$ The DRAP is following the guidelines as recommended by the US FDA and EMA for the use of BSM in Pakistan. The developing countries like Pakistan have a limited budget for healthcare expenditures, drug development, and regulatory policies, and a population earning lower-income, seeks out to get advantages from these rapidly growing products. ${ }^{8,9}$ Besides, a rise in demand for highly valued BSMs such as anti-diabetic, antiasthmatic, cardiovascular, and anticancer medications have pushed pharmaceutical manufacturers towards BSMs development. ${ }^{11}$

As more BSMs are brought into practice, continuing medical education of healthcare providers is fundamental to guarantee patient safety. ${ }^{13}$ Pharmacists are an integral educator, trailblazer, and advocate of biosimilar integration into clinical practice across all settings. They can play a significant role in the clinical utilization of BSMs to guarantee that safe and cost-effective drugs are available for the patients. Hence, it is worthy of discovering where pharmacists presently rate their knowledge about BSMs. With this background, the study was conducted to assess the pharmacists' knowledge, attitude, and practices of integrating BSMs into clinical practice.

\section{Methods}

The cross-sectional study was conducted from August 2019 to November 2019. Different pharmacists working in hospitals and clinics, community pharmacies, and academic settings in Karachi were approached. The pharmacists were provided the survey forms by two researchers of the current study, and for those pharmacists who were busy, the questionnaire was left with them and collected after their proposed time. The ethical approval was obtained from the Institutional Review Board of Darul Sehat Hospital, Karachi, and written consent was obtained from each respondent before the start of the study. Raosoft sample size calculator was used to calculate the sample size by utilizing a confidence level of $90 \%$ the base sample size was evaluated to be $n=267$ with a $5 \%$ margin error. ${ }^{14}$ The approach of convenience sampling was used for the study. The inclusion criteria were that the respondents should be registered pharmacists, and willing to participate in the 
study. Earlier consent was obtained from the different heads of departments in the hospitals, clinics, universities, and pharmacies before initiating the study. The respondents were brief about the purpose of the study and assured that identification of their working place to be kept anonymous.

A 30-item survey form was developed using the literature from the previous studies ${ }^{1,15}$ under the opinions of experts include five senior pharmacists. On completing the content validity, the questionnaire was pre-tested in a smaller sample of pharmacists $(n=30)$, to evaluate the transparency and clarity of question items (face validity). The Hoyt method $\lambda 3$ \{displaystyle lambda_\{3\}\} reliability scale was used for these 30 pharmacists, and the value for the reliability was found to be 0.783 , which is acceptable to accomplish the goals of the present study. ${ }^{16}$ Accompanied by the five questions related to the demographic information of respondents, the survey consisted of 3 sections. The first part includes ten close-ended questions with the options of true, false, and do not know to probe the knowledge of respondents towards BSMs and their concern towards its safety and efficacy. Their level of knowledge was scored " 1 " for every right answer and scored " 0 " for inappropriate or do not know responses. The maximum cumulative knowledge score (BSM) was 10 since there were ten questions to evaluate the knowledge of respondents towards BSM. The overall \% knowledge score (Score obtained/BSM $\times 100)$ for each respondent was calculated and their knowledge was regarded as good (score $\geq 70 \%$ ), fair (score in between $50.1 \%$ and $69.9 \%$ ) and poor (score $\leq 50 \%$ ). A parallel scoring system has been formerly used in another study. ${ }^{17}$ The second section comprises ten questions using a 5-point Likert scale with scoring strongly agree $=5$ to strongly disagree $=1$ that evaluate pharmacists' attitude and perception of importance and confidence towards BSMs, their likelihood of switching to BSM during treatment, shared decision-making practices and rationality of using BSMs in a practice setting. The third section involves five questions regarding their sources of information, motivation factors, and barriers perceived by them for the use of BSMs. The answers obtained from the respondents were entered into the SPSS for Windows version 24.0.0 (SPSS, Inc., Chicago, IL, USA) for analysis. Pearson correlation and independent sample $t$-test were used to identify the relationship among independent variables and the responses, considering $p$ values $<0.05$ as statistically significant.

\section{Results}

In the present study, the pharmacists working in twelve clinics/ hospitals, fifteen pharmacies, and seven academic institutes of Karachi were requested to participate in the study. Out of them, 28 pharmacists did not show their willingness to participate after initial contact; 17 pharmacists did not complete the survey and hence exempted. Lastly, 305 completed surveys were incorporated in the study with a response rate of $87.14 \%$. Amongst them, 39 (12.78\%) were community pharmacists who were delivering their services in different community pharmacies of Karachi, 85 (27.86\%) were academic pharmacists who were providing their services in universities, 54 $(17.7 \%)$ were clinical pharmacists who were working in different hospitals of Karachi and 127 (41.63\%) were fresh pharmacy graduates/trainees (Table 1). The mean age of the respondents was $32.17 \pm 4.49$ years.

The mean cumulative knowledge score (BSM) was $7.93 \pm 1.17$. The percentage of respondents with good knowledge was $81.55 \%$, while $15.08 \%$ and $2.39 \%$ of respondents had fair and poor knowledge, respectively (Table 2). The clinical pharmacists were more knowledgeable as compared to the pharmacists working in the community and academic settings $(p=0.001)$. Around $81 \%$ of respondents were found to be in favor of promoting the use of BSMs in treatment and $78 \%$ of respondents trusted that BSMs are safe. The clinical pharmacists $(p=0.005)$ having more experience $(p=0.002)$ were more likely to

Table I Characteristics of Study Population

\begin{tabular}{|l|l|}
\hline Characteristics & Frequency (\%) \\
\hline $\begin{array}{l}\text { Gender } \\
\text { Males }\end{array}$ & $74(24.26)$ \\
Females & $231(75.73)$ \\
\hline Organization & \\
Private & $263(86.22)$ \\
Public sector & $42(13.77)$ \\
\hline Field/Profession & \\
Community Pharmacists & $39(12.78)$ \\
Clinical pharmacists & $54(17.7)$ \\
Academicians & $85(27.86)$ \\
Fresh pharmacy graduates/trainees & $127(41.63)$ \\
\hline Experience & \\
Less than 5 years & $201(65.90)$ \\
$5-10$ years & $73(23.93)$ \\
10-15 years & $26(8.52)$ \\
I5-20 years & $3(0.98)$ \\
20 years and above & $2(0.65)$ \\
\hline
\end{tabular}


Table 2 Respondents' Knowledge of Biosimilar Medicines and Interchangeable Products

\begin{tabular}{|l|l|}
\hline Knowledge Statement & $\begin{array}{l}\text { Correct } \\
\text { Responses }\end{array}$ \\
\hline BSMs are FDA approved versions of original biological products manufactured after the expiry of original product's patent. & $255(83.60)$ \\
BSM has no significant clinical differences from the reference product & $267(87.54)$ \\
BSM is structurally identical to its reference medicinal product & $230(75.40)$ \\
BSMs are same as interchangeable products & 25 ( 82.29$)$ \\
BSM is a drug for which assessment of biosimilarity requires more comprehensive data compared to generic drugs & $224(73.44)$ \\
All FDA-approved BSMs undergo an extensive assessment to make sure that patients can trust their efficacy, safety, and quality. & $272(89.18)$ \\
Biosimilarity is established through extensive analytical preclinical and clinical studies & $233(76.39)$ \\
BSM can be used in patients who have been treated previously with the reference product & $247(80.98)$ \\
An interchangeable product is a BSM product fulfilling additional requirements as described by the Biologics Price Competition & 21 ( (69.18) \\
and Innovation Act & 229 (75.08) \\
Pharmacist can substitute the interchangeable product for the reference product without referring the prescriber & \\
\hline
\end{tabular}

trust the efficacy and safety of BSMs. The major sources of information stated by respondents were scientific publications/self-study (72.4\%, [95\% CI 69.6-75.2]), pharmaceutical organizations (68.3\%, [95\% CI 65.2-71.4]), colleague/peer pharmacists $(45.8 \%$, [95\% CI 42.9-48.7]), and continuous training (37.4\%, [95\% CI 34.2-40.6]). More than $50 \%$ of respondents opined that patients could be safely switched to BSM during their treatment if the BSM has a similar clinical outcome. More than $90 \%$ believed that pharmacists can contribute significantly in deciding to use specific BSM in treatment (Table 3). The experienced pharmacists were more optimistic as compared to the fresh pharmacists $(p=0.003)$. More than $70 \%$ of respondents perceived that BSMs increase patients' access to a variety of treatment options and encourage competition among companies, which contributes to the reduction of product prices. The clinical pharmacists were more likely to suppose that the BSM increases a variety of treatment options $(p=0.001)$. Around half of the respondents (48.9\%, [95\% CI 46.6-51.2]) were confident in using BSM once approved by the US FDA. The experienced pharmacists were more likely to favor the use of BSMs as compared to fresh graduates $(p=0.004)$. However, the respondents were concerned about the drug safety profile $(45.2 \%$, [95\% CI 42.1-48.3]), quality issues (30.2\%, [95\% CI 28.3-32.1]), and efficacy of BSM (32.3\%, [95\% CI 31.2-37.5]).

More than $85 \%$ considered it worthy for patients to participate in shared decision-making when deciding to use a BSM in their treatment. Figure 1 illustrates the responses of pharmacists towards the rationality/reasons for BSM. The respondents majorly supported to use BSMs to save treatment cost of a patient $(59.2 \%$, [95\% CI
57.3-61.1]), to stimulate competition in the biological market (45.1\%, [95\% CI 42.4-47.8]), and to offer alternatives in case of drug shortage (43.2\%, [95\% CI 41.145.3]). The potential risk of unexpected adverse effects among patients (66.5\%, [95\% CI 64.1-68.9]) was the majorly observed barrier as perceived by the respondents. Other majorly seen barriers include the quality concerns for BSMs (52.4\%, [95\% CI 49.3-55.5]) and lack of their confidence in achieving the pre-determined treatment goals (41.3\%, [95\% CI 38.5-44.1]) (Figure 2)

\section{Discussion}

Our investigation provided a snapshot of pharmacists' knowledge, attitude, and practice related to BSMs. Scanty studies related to BSM have been direct till todate, and ours is the first questionnaire study on this subject among the pharmacists working in Pakistan. The outcomes of the current research reported a considerable understanding of BSMs among pharmacists; since more than $80 \%$ of respondents have good knowledge about the definition, characteristics, safety and efficacy, compatibility, cost issues, and utilization of BSMs. Other studies stated the similar findings representing more than $90 \%$ of respondents were familiar with the definition, guiding principles, and application of BSMs. ${ }^{1,18}$ Another study reported alternate research outcomes in which $46 \%$ of the participants had only a basic knowledge of biological medicines, whereas $43 \%$ had a comprehensive understanding. ${ }^{19}$ The clinical pharmacists in the current study were more knowledgeable as compared to the community and academic pharmacists $(p=0.001)$. The findings of one more study were corresponding to our revealing that community pharmacists were less conversant with 
Table 3 Respondents' Attitude Towards the Use of Biosimilar Medicines and Interchangeable Products

\begin{tabular}{|c|c|c|c|c|c|}
\hline Attitude Statements & $\begin{array}{l}\text { Strongly } \\
\text { Agree }\end{array}$ & Agree & $\begin{array}{l}\text { Neither } \\
\text { Agree Nor } \\
\text { Disagree }\end{array}$ & Disagree & $\begin{array}{l}\text { Strongly } \\
\text { Disagree }\end{array}$ \\
\hline I am in favor of promoting the use BSMs in patient care & $125(40.98)$ & I2I (39.67) & 35 ( 11.47$)$ & $18(5.9)$ & $6(1.96)$ \\
\hline I think that BSMs increase patients' access to variety of treatment options & $119(39.01)$ & $106(34.75)$ & $49(16.06)$ & $21(6.88)$ & $10(3.27)$ \\
\hline $\begin{array}{l}\text { I think that BSMs encourage competition among companies, which } \\
\text { contributes to the reduction of product prices }\end{array}$ & $97(31.80)$ & $142(46.55)$ & $36(11.80)$ & $19(6.22)$ & II (3.60) \\
\hline I think that BSMs should only be used when original drug in ineffective & $63(20.65)$ & $23(7.54)$ & $51(16.72)$ & $68(22.29)$ & $100(32.78)$ \\
\hline $\begin{array}{l}\text { If the US FDA approved a BSM as an interchangeable, I would use it } \\
\text { interchangeably with the reference biological product }\end{array}$ & $80(26.22)$ & $149(48.85)$ & $36(11.8)$ & $37(12.13)$ & $3(0.98)$ \\
\hline $\begin{array}{l}\text { I believed that patients can be safely switched to BSM during treatment } \\
\text { with the same clinical outcome }\end{array}$ & $64(20.98)$ & III (36.39) & $78(25.57)$ & $44(14.42)$ & $8(2.62)$ \\
\hline Being a pharmacist, I can safely switch to BSMs without physician permission & $4(1.31)$ & $21(6.88)$ & I8I (59.34) & $47(15.40)$ & $52(17.04)$ \\
\hline $\begin{array}{l}\text { I think pharmacists can contribute significantly in deciding to use } \\
\text { specific BSM in treatment }\end{array}$ & $172(56.39)$ & $108(35.40)$ & $16(5.24)$ & $6(1.96)$ & $3(0.98)$ \\
\hline $\begin{array}{l}\text { I think that the patient should participate in shared decision-making } \\
\text { when deciding to use BSM in their treatment }\end{array}$ & $93(30.49)$ & $169(55.4)$ & $25(8.19)$ & II (3.6) & $7(2.29)$ \\
\hline $\begin{array}{l}\text { I think that the healthcare professionals should be further educated to } \\
\text { eliminate potential misconceptions and integrate BSMs into routine } \\
\text { clinical practice }\end{array}$ & $174(57.04)$ & $88(28.85)$ & $17(5.57)$ & $20(6.55)$ & $6(1.96)$ \\
\hline
\end{tabular}

BSMs as compared to pharmacists working in clinical settings. $^{20}$ Pharmacists must have in-depth knowledge about the guidelines and rational use of BSMs; since they have to contribute significantly to the use of such medicines in clinical practice. An approved BSM is predictable to have identical efficacy and safety as the original biological product; however, it may not necessarily be appropriate for all the indications as to its original biologic product. $^{21}$ Therefore, a pharmacist must be well conversant with the advancement in the current practice of BSMs to make sure their optimum and safe usage.

The general safety issues related to biopharmaceuticals are immune system disorders and infections. ${ }^{22}$ All biological drugs may stimulate an immune reaction that is potentially serious and may be life-threatening; though anaphylaxis, allergy and serum sickness are currently

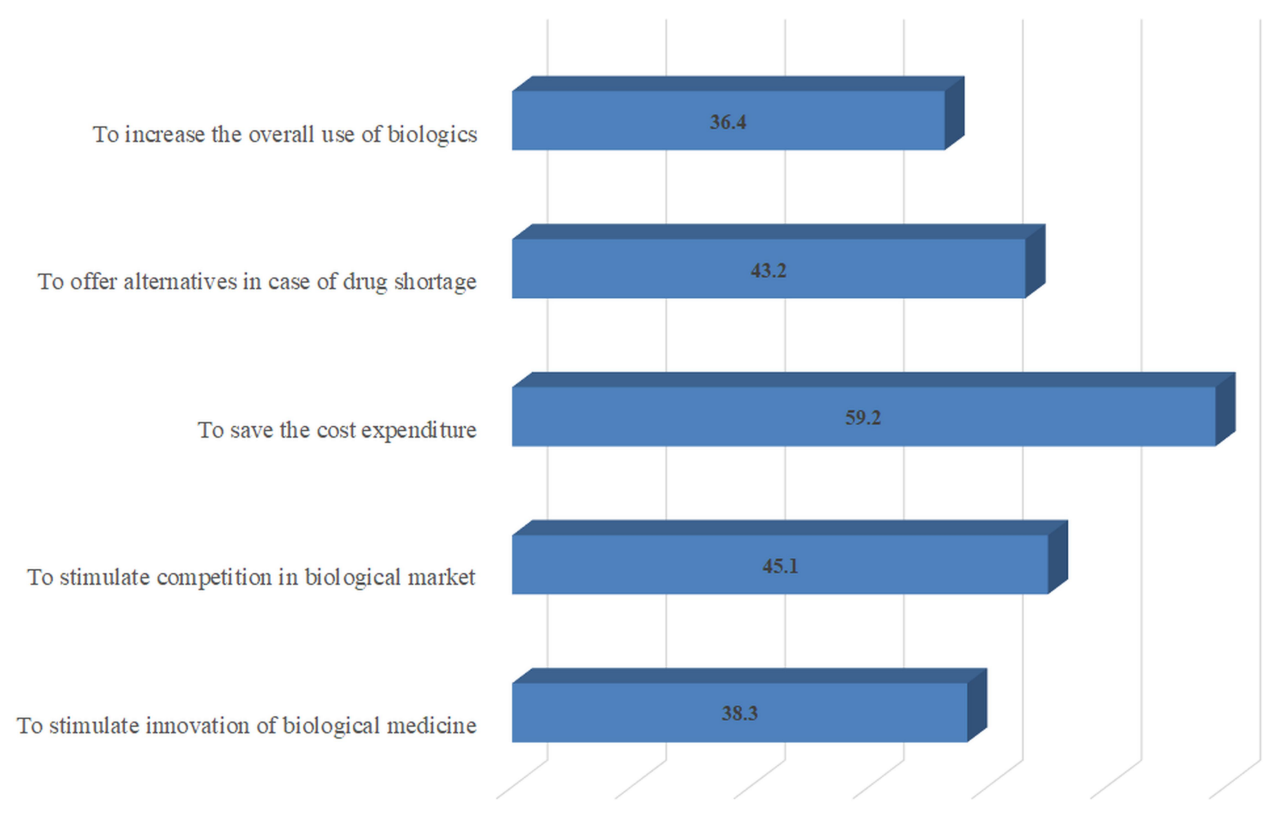

Figure I Respondents' perceived reasons of encouraging the use of Biosimilar Medicines (\%). 


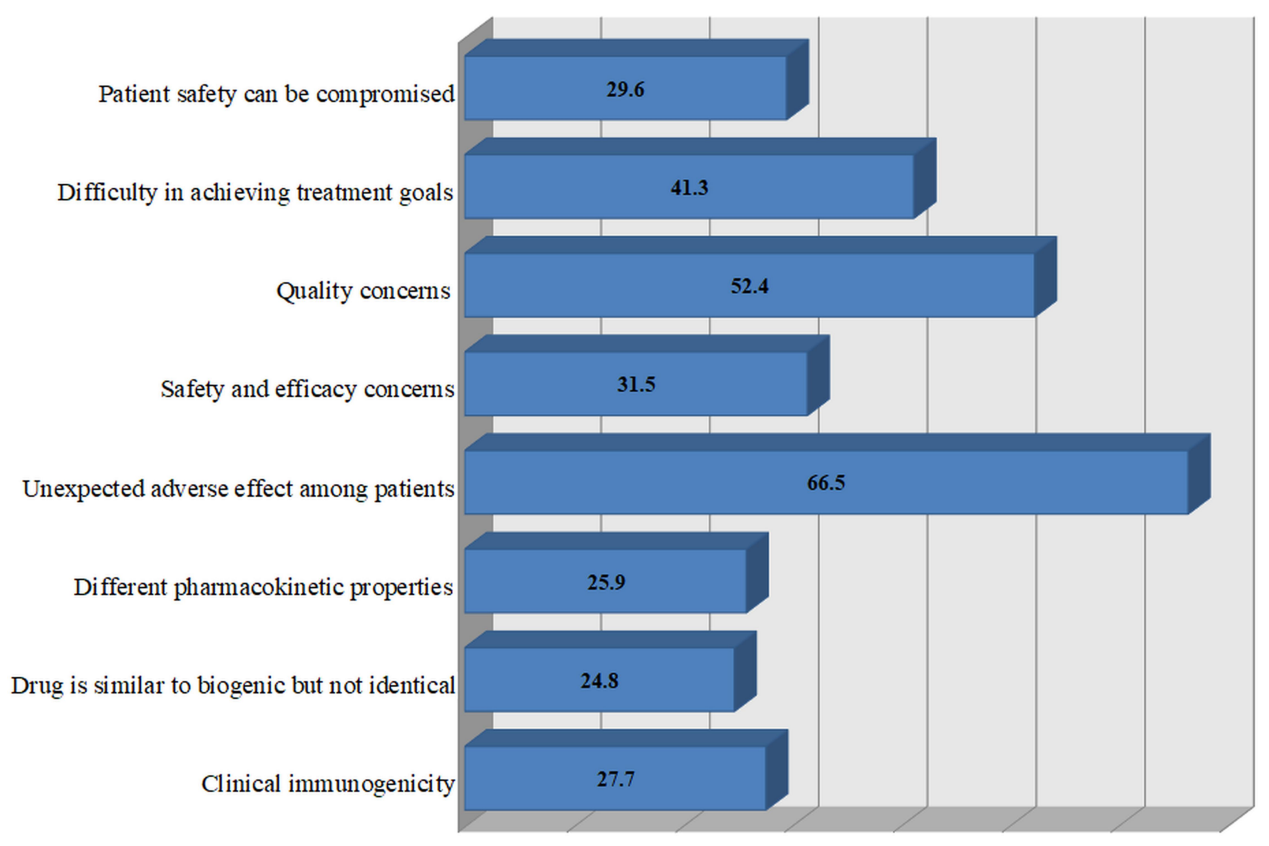

Figure 2 Respondents' perceived barriers of using Biosimilar Medicines (\%).

rare because of the quality procedures involved in the developments and purity of biopharmaceuticals. ${ }^{23,24}$ All FDA-endorsed BSMs undergo a thorough assessment with the goal that patients get satisfied with the quality attributes, safety, and effectiveness of these products. A BSM is generally alike in effectiveness, quality, and safety attribute with the reference product. ${ }^{25}$ In the current study, the majority of the respondents trusted that all FDAapproved BSMs, undertakes an extensive assessment to endorse that patients can trust their efficacy, quality, and safety. Similar findings were reported by Cohen, that most respondents $(75 \%)$ seem to confide in FDA endorsement choices; however, they claim the need for additional information when settling on the treatment decisions. ${ }^{1}$ In the present study, around half of the respondents claimed themselves self-assured and likely to use BSM in a practice setting. Another study reported that a majority of the study population were uncertain about the safety of BSMs that could be due to their lack of information regarding current prevailing practices of BSMs. ${ }^{1}$

There are likewise reasonable issues that influence the implementation of BSM, for example, an absence of precise regulatory direction on how to best deal with the switchover between different BSMs in institutions. Due to the complexity in the regulatory pathways globally, there is an active discussion worldwide on appropriate substitution policies for BSMs. Substitution is defined as the practice where a pharmacist can decide to replace a product, or dispensing a highly similar BSM without the prior consent of prescribing physician. ${ }^{11}$ As the BSMs have a complex nature, pharmacy-mediated substitution is inappropriate unless stringent legal and regulatory standards with the appropriate requirements of biosimilarity are satisfied. ${ }^{26}$ In Pakistan, a prescriber is a sole decision-maker for the healthcare requirements of a patient; and has the authority to choose which precise medication, comprising the pharmacological class and brand of a medication, is to prescribe to the patient. Hence, in countries like Pakistan, where no added scientific standard exists for BSM substitution, the physician remains actively involved in treatment choices. The choice of substituting the BSMs by the pharmacist was another focus of our study, as they are eventually accountable for the execution of substitution policy at the pharmacy level. More than $50 \%$ of respondents believed that patients could be switched safely to BSM without any risk. Another study reported physicians' belief that substitution of BSM by a pharmacist would not be appropriate and the choices of this nature must be made by the prescriber, both on treatment inception and during a patient's treatment course, since the BSMs may not be having a similar structure to their reference product. ${ }^{26} \mathrm{~A}$ majority of Irish pharmacists revealed their confidence in switching to an alternate patient's medication from an originator to a BSM with the mutual consensus of the prescriber. ${ }^{26}$ Chapman et al reported that safety and efficacy fears were developed 
among several prescribers in substituting rather than commencing the use of BSMs. ${ }^{20}$ Almost certainly, a few respondents were uninformed of two elements: (1) the prime sequence of a BSM must be identical to the reference, and (2) that the quality traits of all biologics (both originator biologics and BSMs) may frequently vary for every batch; but inside predetermined limitations, and variability may not compromise the safety concerns. ${ }^{27,28}$

In the current study, more than $85 \%$ of respondents considered it worthy for the patient to participate in shared decision-making when deciding to use a BSM. Another study reported parallel findings that half of the participants seem convinced with the importance of shared decisionmaking with patients. ${ }^{29}$ As BSM is less costly than the originator, the cost-effectiveness of a BSM may be subject to its relative effectiveness. If the clinical studies prove corresponding effectiveness between BSM and the originator, then a cost-minimization analysis recognizes BSM to be the minimum expensive medication. ${ }^{30}$ Our respondents discoursed that the main reason for their inclination to support the use of BSM in their practice is its costeffectiveness (59.2\%); however, their other motivations were to stimulate competition in the biological market and to propose replacements in the instance of drug unavailability. One study illustrated that the effectiveness of BSM in extrapolated indications, immunogenicity, safety profile, and quality, is among the accompanying general issues regarding BSMs. ${ }^{31}$ The potential risk of unexpected adverse effects among patients was the main barrier of using BSM reported in our study. Likewise, findings similar to ours were reported in another study. ${ }^{32}$ The respondents' concern in the current study about the potential risk of unexpected adverse effects might be because the quality issues of pharmaceutical products and the availability of biomimics are flags as the main problem in underdeveloped countries like Pakistan. Studies have revealed that biomimics products can have changed both clinically and structurally as compared to the reference product and can compromise patient safety as they are cheap and might be the only treatment choice available to patients due to limitations of resources. ${ }^{33}$ Pharmacists have adequate involvement with patient-care; they have an important job in dealing with the BSMs, and further advancing their understanding towards the rational BSM utilization will permit them to settle on sensible choices concerning formulary consideration and teach patients and other healthcare professionals about BSMs.

\section{Conclusions}

The findings revealed that pharmacists were well informed about the BSMs. However, some of the responses to the attitude demonstrated a lack of understanding of the application of that knowledge. Numerous pharmacists were agreeable to execute the usage of BSMs in their practice and persuaded of BSM cost-saving potential. They were concerned for further advancing their comprehension to guarantee the safe utilization of these specific medications.

\section{Acknowledgment}

The author would like to acknowledge TWAS (The World Academy of Sciences) for providing the opportunity to conduct this research work.

\section{Disclosure}

The authors report no conflicts of interest in this work.

\section{References}

1. Cohen H, Beydoun D, Chien D, et al. Awareness, knowledge, and perceptions of biosimilars among specialty physicians. Adv Ther. 2016;33(12):2160-2172. doi:10.1007/s12325-016-0431-5

2. Boone N, van der Kuy H, Scott M, et al. How to select a biosimilar. Eur J Hosp Pharm Sci Pract. 2013;20(5):275-286. doi:10.1136/ejhpharm-2013-000370

3. Wiland P, Batko B, Brzosko M, et al. Biosimilar switching-current state of knowledge. Reumatologia. 2018;56(4):234. doi:10.5114/ reum.2018.77975

4. Grabowski HG, Kyle M, Mortimer R, Long G, Kirson N. Evolving brand-name and generic drug competition may warrant a revision of the Hatch-Waxman Act. Health Aff. 2011;30(11):2157-2166. doi:10. 1377/hlthaff.2010.0270

5. Stevenson JG, Popovian R, Jacobs I, Hurst S, Shane LG. Biosimilars: practical considerations for pharmacists. Ann Pharmacother. 2017;51 (7):590-602. doi:10.1177/1060028017690743

6. Colbert RA, Cronstein BN. Biosimilars: the debate continues. Arthritis Rheum. 2011;63(10):2848-2850. doi:10.1002/art.30505

7. Falit BP, Singh SC, Brennan TA. Biosimilar competition in the United States: statutory incentives, payers, and pharmacy benefit managers. Health Aff. 2015;34(2):294-301. doi:10.1377/hlthaff.2014. 0482

8. Crommelin DJ, de Vlieger JS, Weinstein V, Mühlebach S, Shah VP, Schellekens H. Different pharmaceutical products need similar terminology. AAPS J. 2014;16(1):11-14. doi:10.1208/s12248-0139532-0

9. Shakeel S, Iffat W, Ahmed H. Biosimilar products' application in advanced drug therapy; a qualitative insight. J Med Diagn Meth. 2016;5(199):2

10. Wang J, Chow S-C. On the regulatory approval pathway of biosimilar products. Pharmaceuticals. 2012;5(4):353-368. doi:10.3390/ph5040 353

11. Patel PK, King CR, Feldman SR. Biologics and biosimilars. J Dermatolog Treat. 2015;26(4):299-302. doi:10.3109/09546634. 2015.1054782

12. Grabowski H, Guha R, Salgado M. Biosimilar Competition: Lessons from Europe. Nature Publishing Group; 2014. 
13. Chow SC, Wang J, Endrenyi L, Lachenbruch PA. Scientific considerations for assessing biosimilar products. Stat Med. 2013;32 (3):370-381. doi:10.1002/sim.5571

14. Omair A. Sample size estimation and sampling techniques for selecting a representative sample. J Health Spec. 2014;2(4):142. doi:10. 4103/1658-600X.142783

15. Beck M, Michel B, Rybarczyk-Vigouret M-C, et al. editors. Knowledge, Behaviors and Practices of Community and Hospital Pharmacists Towards Biosimilar Medicines: Results of a French Web-Based Survey. MAbs. Taylor \& Francis; 2017

16. Namdeo SK, Rout SD. Calculating and interpreting cronbach's alpha using rosenberg assessment scale on paediatrician's attitude and perception on self esteem. Int J Community Med Public Health. 2016;3(6):1371-1374. doi:10.18203/2394-6040.ijcmph20161448

17. Mallhi TH, Khan YH, Tanveer N, et al. Awareness and knowledge of Chikungunya infection following its outbreak in Pakistan among health care students and professionals: a nationwide survey. PeerJ. 2018;6:e5481. doi:10.7717/peerj.5481

18. Ismailov RM, Khasanova ZD. Biosimilar knowledge among oncology/hematology team members in Colorado, USA: an educational initiative and follow-up survey. BioDrugs. 2018;32(5):499-506. doi:10.1007/s40259-018-0301-6

19. Jensen AR. Biosimilar product labels in Europe: what information should they contain? GaBI J. 2017;6(1):38-41. doi:10.5639/gabij. 2017.0601.008

20. Chapman SR, Fitzpatrick RW, Aladul MI. Knowledge, attitude and practice of healthcare professionals towards infliximab and insulin glargine biosimilars: result of a UK web-based survey. BMJ Open. 2017;7(6):e016730. doi:10.1136/bmjopen-2017-016730

21. Wilson P, Wood C. Biosimilar ESAs: a comparative review. J Ren Care. 2015;41(1):53-61. doi:10.1111/jorc.12099

22. Süle A, Jørgensen F, Horák P, Peppard J, Kohl S. Biosimilar medicines. Eur J Hosp Pharm. 2019;26(2):117-118.

23. Al-Sabbagh A, Olech E, McClellan JE, Kirchhoff CF, editors. Development of biosimilars. Semin Arthritis Rheum. 2016;45(5): S11-S18. doi:10.1016/j.semarthrit.2016.01.002.
24. Jarrett S, Dingermann T. Biosimilars are here: a hospital pharmacist's guide to educating health care professionals on biosimilars. Hosp Pharm. 2015;50(10):884-893. doi:10.1310/hpj5010-884

25. Casadevall N, Edwards IR, Felix T, et al. Pharmacovigilance and biosimilars: considerations, needs and challenges. Expert Opin Biol Ther. 2013;13(7):1039-1047. doi:10.1517/14712598.2013.783560

26. O'Callaghan J, Bermingham M, Leonard M, et al. Assessing awareness and attitudes of healthcare professionals on the use of biosimilar medicines: a survey of physicians and pharmacists in Ireland. Regul Toxicol Pharmacol. 2017;88:252-261. doi:10.1016/j.yrtph.2017.06. 013

27. Schiestl M, Stangler T, Torella C, Čepeljnik T, Toll H, Grau R. Acceptable changes in quality attributes of glycosylated biopharmaceuticals. Nat Biotechnol. 2011;29(4):310-312. doi:10.10 38/nbt. 1839

28. de Abreu MM, Strand V, Levy RA, Araujo DV. Putting the value into biosimilar decision making: the judgment value criteria. Autoimmun Rev. 2014;13(6):678-684. doi:10.1016/j.autrev.2014.01.051

29. Cook JW, McGrath MK, Dixon MD, Switchenko JM, Harvey RD, Pentz RD. Academic oncology clinicians' understanding of biosimilars and information needed before prescribing. Ther Adv Med Oncol. 2019;11:1758835918818335. doi:10.1177/1758835918818335

30. Simoens S. Biosimilar medicines and cost-effectiveness. Clinicoecon Outcomes Res. 2011;3:29. doi:10.2147/CEOR.S12494

31. Weise M, Kurki P, Wolff-Holz E, Bielsky M-C, Schneider CK. Biosimilars: the science of extrapolation. Blood. 2014;124(22): 3191-3196.

32. Aladul MI, Fitzpatrick RW, Chapman SR. Healthcare professionals' perceptions and perspectives on biosimilar medicines and the barriers and facilitators to their prescribing in UK: a qualitative study. $B M J$ Open. 2018;8(11):e023603. doi:10.1136/bmjopen-2018-023603

33. Foreman E, Patel H, Siderov J, Harchowal J, Bubalo J, Chan A. A survey of global biosimilar implementation practice conducted by the International society of oncology pharmacy practitioners. J Oncol Pharm Pract. 2020;26(3_suppl):22-32. doi:10.1177/107815522091 3098
International Journal of General Medicine

\section{Publish your work in this journal}

The International Journal of General Medicine is an international, peer-reviewed open-access journal that focuses on general and internal medicine, pathogenesis, epidemiology, diagnosis, monitoring and treatment protocols. The journal is characterized by the rapid reporting of reviews, original research and clinical studies across all disease areas. The manuscript management system is completely online and includes a very quick and fair peer-review system, which is all easy to use. Visit http://www.dovepress.com/ testimonials.php to read real quotes from published authors. 